\title{
Twenty-five years of the Education and the Information Technologies journal: Past and future
}

\author{
Arthur Tatnall $^{1}$ (D) $\cdot$ Andrew Fluck $^{2}$ (D)
}

Received: 24 November 2021 / Accepted: 25 January 2022 /Published online: 3 February 2022

(c) The Author(s) 2022

\begin{abstract}
This article examines how research publications in education and information technologies have changed over the last twenty-five years. The authors investigate articles published in the journal: Education and Information Technologies (EAIT). To celebrate a quarter-century of this publication. They take a retrospective view of the EAIT journal, using Historical Research methodology to show some of the trends in topics covered and to interrogate the expanding cultural background of published authors. While computer technology has developed rapidly over this time, research methodologies, international collaborations, and discipline areas have multiplied quickly. Finally, this article identifies some unique papers that have appeared in print and provides glimpses into what the future may hold.
\end{abstract}

Keywords Education - Information technologies · EAIT journal $\cdot$ Higher education . Schools $\cdot$ Historical research

\section{Introduction}

This article explains how research interest and publication on different topics in education and information technologies have changed over the last twenty-five years. To do so, it looks at articles published in this journal: Education and Information Technologies (EAIT). This exploration, of course, has somewhat of a limitation as there are other journals also dealing with this topic. However, the focus and range of EAIT's articles over this period are typical of the times. They still provide a good indication of the advances that education and information technologies have made

Arthur Tatnall

Arthur.Tatnall@vu.edu.au

Andrew Fluck

Andrew.Fluck@utas.edu.au

1 Victoria University, Melbourne, Australia

2 University of Tasmania, Launceston, Australia 
over this period and problems that researchers have regarded as essential to educational progression. These articles offer a view across this period to see how education and information technologies have changed and continued to develop over the last twenty-five years.

\section{Beginnings}

Although it is possible to speak of information technology today, its intrinsic meaning reflects computing. The term also includes other technological devices such as multimedia, video, television, and radio. Oxford University Press defines Information Technology (IT) as "the study or use of computers, telecommunication systems, and other devices for storing, retrieving, and transmitting information" (Oxford Reference, 2021). People often use the term 'information and communication technology' (ICT) to mean much the same thing. The Collins English Dictionary defines ICT as "activities or studies involving computers and other electronic technology" (Collins English Dictionary, 2021).

EAIT is the official journal of the UNESCO-affiliated International Federation for Information Processing (IFIP) Technical Committee on Education (TC3). It was first published in 1996 and so has now seen 25 years of publications. Use of an Historical Research methodology approach to this research (Goldweber et al., 1997; Goodson \& Anstead, 1992; Howell \& Prevenier, 2001) allows interrogation of important article topics and trends, and consideration of the expanding cultural background of published authors. Secondary sources were also used to investigate changes in what others thought of EAIT, and included the number of article downloads (666,155 in 2020), the journals growing high Impact Factor (2.917), and inclusion in the Social Science Citation Index (SSCI) (Web of Science Group, 2020). These increased the journal's attractiveness to researchers and led to more articles submitted.

In relation to Information Technologies, the journal has always attempted to cover all aspects and domains of Education. The editorial of the first issue points out that, in line with the work of IFIP TC3, the journal would cover the application of IT: "in teacher education, in curriculum and instruction for elementary and secondary education, in administration and policy making, in computer science education at the secondary and higher education levels, in research, and in the application domain of distance education" (Collis \& Samways, 1996). Although the number of articles on each of these aspects has varied over the years, the range of coverage has remained wide, covering all these aspects of education.

Many of the early published articles dealt with the technology itself. For example, the first issue of Volume 1 had five articles, beginning with an article pointing out the growing worldwide use of computer networks in education and describing 'Enlaces' as a Chilean project involving educational computing and networking. This work was followed by an article discussing use of Audiographics as an 'Electronic Classroom'. Next is an article investigating use of school-based microcomputers for instructional support. Another article describes AIDA, which is a 'methodology independent support tool for educational software authoring'. The fifth emphasises how it is essential for school principals to act as IT role models. Of the 
five articles, four deal with technology, while the last discusses people and group work with computers in schools.

It was interesting to read in the editorial of this issue (Collis \& Samways, 1996) that "The journal Education and Information Technologies will not only be in paper form but will also develop an Internet available variant". How things have changed!

Other issues in Volume 1 had articles on technology-related topics, including video, hypermedia, virtual classes, multimedia, communication, and educational software selection. However, the other topics were more people-centred, such as educational management, games, computers in the home, and the social and ethical impact of computing. Thus, the journal had, and still has, a very broad interpretation of its title. As the science of computing develops, emerging specialisations proliferate, leading to a divergence of terminology. At the inception of the journal, 'Information Technology' covered both the equipment, techniques and subject area. Modern terminology is currently under discussion by the international coalition 'Informatics for All'. In their strategy paper (Caspersen et al., 2018), their definition is: "This realm of 'digital systems' is driven by scientific laws, as those in the realm of physical machines, which makes up the science called Informatics ... [it is] also known as Computer Science or Computing in USA and elsewhere". In Australian schools, 'Digital Technologies' is the name for the equivalent subject. The journal has retained its original title for consistency, but the aims expanded to include these additional terms. Likewise, Education covers all student ages, abilities, and subject content matter. The current classification scheme for reviewers and manuscripts broadly includes eight characteristics, with 'other' as a choice in each:

- Impact of findings (theoretical, economic, educational impact, geographic)

- Ages/types of intended learners (early childhood to university, inclusive/special needs)

- Intended learning area (applied, natural, social \& formal sciences, humanities, affective domain)

- Role of computer users (educational administrator, teacher, student)

- Type of research project (perceptions, cultural, meta-analysis, improving learning)

- Type of computer system (communications/internet, software, hardware)

- Data collection (database, ethnographic, pre/post-test)

- Research method (qualitative, quantitative, mixed, experimental)

The number of academic articles published over this period has increased dramatically. For example, Volume 1 contained 15 articles; Volume 25 had 268 articles.

\section{International focus}

The journal has always ensured an international focus, with articles coming from researchers around the world. For example, in Volume 1 (1996), articles were from researchers in Australia, Canada, Chile, Finland, Hong Kong, Japan, New Zealand, Portugal, and the USA. Over the past 25 years, researchers from 97 countries have had their work published in the journal. Moreover, the range and number of countries in which this research occurred has dramatically increased over twenty-five years, as shown in Table 1 below. 


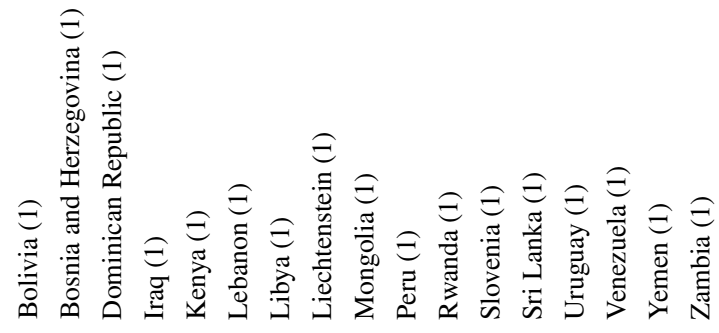

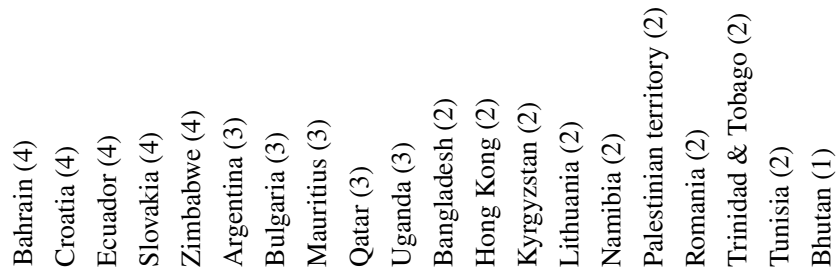

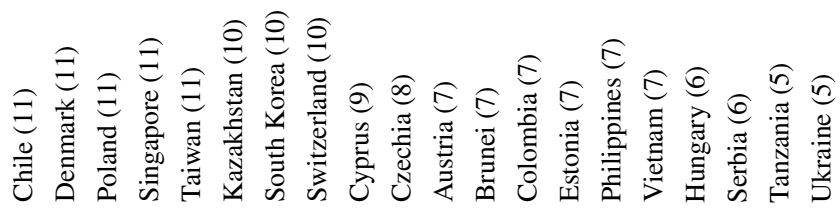

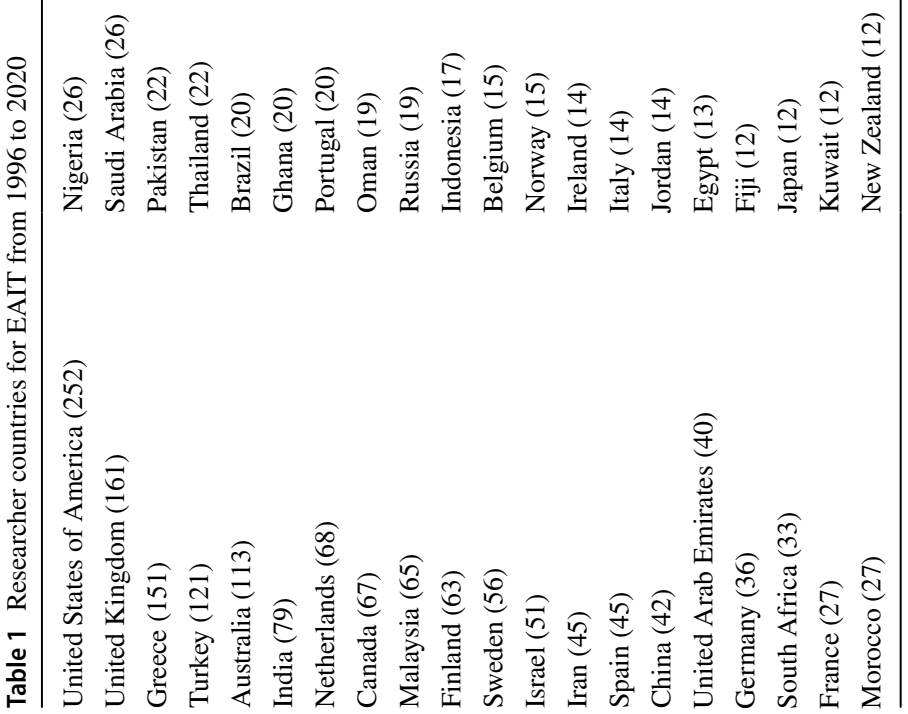


Although all articles in EAIT are published in English, Table 2 shows the transition from anglophone predominance to a broader range of researcher cultural backgrounds.

The scale of international collaborations across research institutions has grown over the 25 years. Table 3 shows this by identifying articles where research organisations of co-authors based in more than one country (having eliminated multiple co-authors from the same country). Some authors submitted articles not based on a research organisation, so these are missing from the table.

This rising trend of international cooperation between co-authors provides readers with an assurance of EAIT's global perspectives. One could only speculate how such partnerships evolved. Perhaps it was the speed or global reach of digital communications; perhaps they developed through personal meetings at international conferences. If the latter, it is possible that we will see a drop in 2020-2022 since travel has been curtailed by pandemic public health rules.

\section{Keyword analysis}

To identify trends in the journal, Table 4 shows the results from a word cloud analysis (https://tagcrowd.com/) of article keywords in each demi-decade.

It is noticeable that the technology (ICT) and the age of students considered (Higher Education) have jostled for position in this keyword analysis. Methodology (case study) only made it into the top six keywords once over the 25 years, in 2001-2005. However, 'education' in different learning formats (collaborative learning, e-learning, distance learning, etc.) constitutes $33 \%$ of these top keywords, a healthy sign of the diversity of learning types published in EAIT. By comparison, technological items occur in $27 \%$ of the table, indicating a good mixture of this other aspect of the journal title. 'Evaluation' has two entries, and both 'Teachers' and 'Research' have one mention each.

\section{Analysis of the changes in articles over the demi-decades}

There have been many changes in education over the last 25 years. Technologies that are in everyday use today were not in existence in the 1990s. Many earlier journal articles dealt with technologies such as multimedia, but this has changed as more now relate to the internet and mobile technologies. The following analyses articles published in each of the demi-decades over the journal's 25 years of existence. It also addresses how the article types have changed. Volumes 1-20 had four issues, rising to six issues in Volumes 21-25. Overall, in the 25 years, a total of 1,415 articles were published. (This included 52 book reviews and information papers.) 
Table 2 Most represented research countries for published articles

\begin{tabular}{llll}
\hline Demi-decade & Most frequent researcher country & $\begin{array}{l}\text { Second most frequent } \\
\text { researcher country }\end{array}$ & $\begin{array}{l}\text { Third most frequent } \\
\text { researcher country }\end{array}$ \\
\hline $1996-2000$ & United Kingdom & Australia & United States of America \\
$2001-2005$ & United Kingdom & Greece & United States of America \\
$2006-2010$ & United Kingdom & United States of America & Greece \\
$2011-2015$ & United States of America & Greece & Netherlands \\
$2016-2020$ & United States of America & Turkey & Greece \\
\hline
\end{tabular}

Table 3 Proportions of international research organisation co-operations

\begin{tabular}{llll}
\hline Demi-decade & $\begin{array}{l}\text { Articles from a single } \\
\text { country }\end{array}$ & $\begin{array}{l}\text { Articles from multiple } \\
\text { countries }\end{array}$ & $\begin{array}{l}\text { Proportion of interna- } \\
\text { tional co-operations }\end{array}$ \\
\hline $1996-2000$ & 87 & 13 & $13 \%$ \\
$2001-2005$ & 65 & 5 & $7 \%$ \\
$2006-2010$ & 91 & 26 & $22 \%$ \\
$2011-2015$ & 176 & 51 & $22 \%$ \\
$2016-2020$ & 537 & 180 & $25 \%$ \\
\hline
\end{tabular}

\subsection{Changes in computer technologies in the last 25 years}

Many of the computer technologies that are the subject of articles today only became available recently. Perhaps the most critical technology for educational computing, other than the computer itself, is the world wide web. This system became operational in 1991, and its use quickly became prevalent in both universities and schools. Some of the applications we use today, however, were much more recent. The invention of international links (hypertext) between digital files has generated Google search (1998) and collaborative documents as found in Wikipedia (2001). Programming languages like Scratch (2003) for early learners are now also online. Social media, such as Facebook (2004), YouTube (2005), and Twitter (2006) have flourished. People used specific user-centric technologies for educational purposes - iPhone (2007), Chrome browser (2008), and iPad (2010). Articles on Massive Open Online Courses (MOOCs) began in 2008 and by 2016 were quite popular and threatened to upset global educational economics. Digital badges appeared as an article topic in 2015. Data mining for school management emerged in 2010, and EAIT first reported mobile learning in 2012. Leaping forward, stealth assessment came in 2019.

Over the years, a wide variety of disciplines have been represented. These included: mathematics, general science, physics, chemistry, foreign languages, English as a foreign language (EFL), business education, engineering, orthodontics, geography, history, biology, bioinformatics, and music. The knowledge trends mapped in the journal show a spiral of increasing specialisation and theoretical proposals followed by empirical investigation. Over the years, the range 


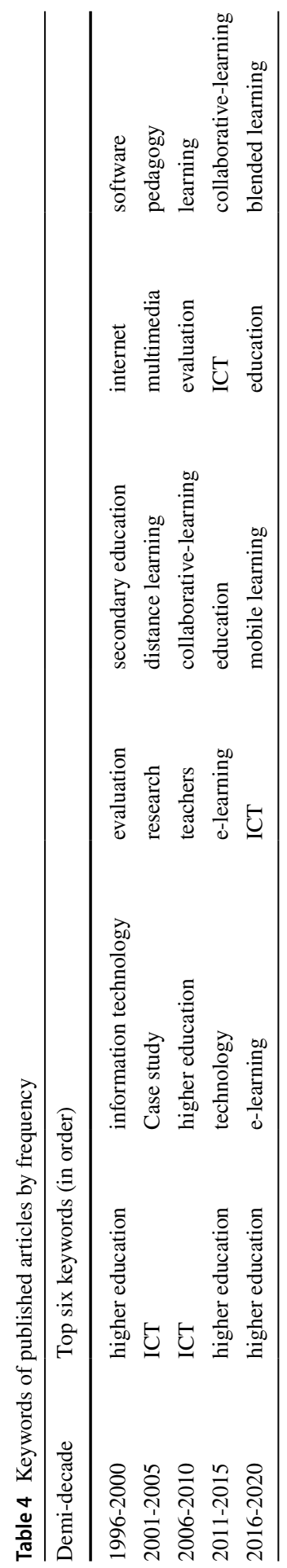


of technologies (software and hardware) has broadened, as have the educational areas of application.

\subsection{Volume 1-5 (1996-2000): Evaluation and software}

Out of the 103 articles in these five volumes (excluding 16 book reviews and IFIP information papers), over $10 \%$ dealt with topics relating to multimedia. A few articles (5) related significantly to the internet and world wide web - a new area then as the web had only recently become operational in education. There were, of course, no articles on mobile technology such as iPads and mobile phones as at that time these were not in existence.

Many articles dealt with teaching, teaching issues, experiences, curriculum, and learning environments. These included an article on disability and: Collaborative skills with a group leader, Social and ethical impact of computing, Online forums, Teachers' computer anxiety, The computer as a toy and at home, Distance education, and The virtual class - another group of articles related to hardware tools, and software. In particular, discussions surrounded the development and selection of educational software.

Articles covered both secondary and higher education. There were four special issues:

- Information Technology and Educational Management

- Human-Computer Interaction (HCI) and Educational Tools: Theory into Practice

- Evaluation

- Virtual Reality

It was a little surprising to see articles on virtual reality as this could be a topic for a later issue. In Volume 1, telephone connections allowed six geographically dispersed people to see the same screen, and was used for teacher professional development (Tiffen, 1996).

\subsection{Volume 6-10 (2001-2005): Case study and pedagogy}

There were 110 articles (and 28 book reviews and IFIP information papers) in these volumes. While there were still a few articles dealing with multimedia the number was less than in 1996-2000. Something new in this period was articles examining the use of information technology in education in different countries: Israel, Egypt, Hong Kong, Turkey, Sweden, France, Germany, Lithuania, Cyprus, and Ireland.

The use of IT in different subject areas was prominent. This included mathematics, general science, chemistry, physics, foreign languages, business education, spreadsheets, music composition, Greek sign language, historical documents, new office technology, robotics, computer engineering, and mechanical interaction.

Several articles discussed Algorithms and Programming, including Rethinking of Teaching Objects-First, Difficulties in Learning and Teaching Programming, 
Introduction to Formal Programming, and Three-Dimensional Program Visualisation for Novice Programmers.

Articles relating to Teaching Issues looked at topics such as synchronous peer interaction, student task modelling, children's conceptions of information communications technology, and students' mental models of the internet. Articles included: Characteristics of Successful Tertiary Online Students, Quality of ICT Teaching within an ICT-Rich Environment, and Bridging the Digital Divide Between Rural and Urban Communities. In addition, there was another article on IT and disability.

Articles also discussed issues for teachers: Impact of New Information Technologies on Teachers and Students, Interaction between Primary Teachers' Perceptions of ICT and Their Pedagogy, Visions for ICT, Ethics and the Practice of Teachers, Inservice Teacher Training, and Email Reducing Stress for Student Teachers.

There were three special issues:

- Networking the Learner

- Secondary Informatics Education

- Learning for the Twenty-first Century: What really matters?

The most significant number of articles though related to Human and Social Issues in Education, on topics such as The Role of Play in the Pedagogy of ICT, Lifelong Learning, Classroom Practice and the Ownership and Use of Personal Computers, Technology's Non-Neutrality, Students' Perceptions of Technological Supports. Articles included: Student Interaction Using Student Groups and Peer Review over the Internet, Managing the Social and Cultural Consequences of Introducing Groupware Technology into the Group Learning Environment, Is Doing More Important than Knowing?, and Speed of Interaction and Relative Number of Mistakes as Indicators of Learning Results.

Of particular interest was an article titled: "The Machine Stops": One School's Rejection of Integrated Learning Systems. This case study found technical difficulties and value for money were insurmountable challenges.

Again, the articles covered all levels of education, from primary to tertiary.

\subsection{Volume 11-15 (2006-2010): Collaboration and learning efficacy}

This set included 105 articles in these volumes (plus eight book reviews). A significant change was the number of articles explicitly mentioning formal research. Of course, all articles are research-based in a journal, but some are more explicitly so than others. Articles with titles such as Building interfaces for on-line collaborative learning were common.

As in the last demi-decade, some articles dealt with education and information technologies in different countries and regions: Sweden, Norway, Hong Kong, USA, Europe, Germany, Denmark, South Africa, China, Greece, Zimbabwe, Taiwan, and Thailand. Educational policy in Denmark was also the subject of an article: ICT-use, educational policy and changes in pedagogical paradigms in compulsory education in Denmark: From a lifelong learning paradigm 
to a traditional paradigm? There was also an overall comparative article and a special issue on Pedagogical practices and ICT use around the world: Findings from the IEA international comparative study SITES2006.

The number of articles examining specific subjects was less, including only physics, mathematics, and chemistry. However, the number of articles dealing with informatics and computer science began to grow. Very few articles looked at multimedia, showing that people viewed this as of decreasing importance. One article investigated: Empowering student learning through Tablet PCs $-A$ case study. This publication occurred just as the iPad began to appear. There was also an article exploring the use of interactive whiteboards. Finally, a couple of articles looked at distance education and virtual learning environments. This number increased significantly in later demi-decades.

There were five special issues:

- Imagining the Future for ICT and Education

- Impact of ICT and Digital Resources

- Valuing Individual and Shared Learning: The Role of ICT

- Pedagogical Practices and ICT Use Around the World: Findings from the IEA International Comparative Study SITES2006

- Information Systems Curriculum

As in the last demi-decade, many articles discussed teaching and teachers. Some articles dealt with teacher education (both preservice and ongoing) in the use of IT. The topics included distance-based teacher training programs, teaching for blended learning, ICT pedagogy, cultural and organisational issues facing online learning communities of teachers, learners and instructors, and qualifying online teachers. Articles included: Student teachers go online, Teaching teachers to teach ICT integration, Training with ICT from the trainee's perspective, Situated learning and teachers' digital competence, The conceptualization of instructional technology by teacher educators in Zimbabwe, and The digital challenges of school and teacher education in Norway - "Whatever Happened to the Social Dimension?"

Again, human and social issues relating to education and information technologies were the subject of many articles, including topics such as: Learning in a Distance-based Teacher Training Programme, Interactive learning environments for children with visual disabilities, Children's conceptualisation of computers and how they work, and Is information acquisition still crucial in the information age? In addition, evaluative articles included: The impact of virtual reality on parents' awareness of cognitive perceptions of a dyslectic child, The impact of virtual reality on the awareness of teenagers to social and emotional experiences of immigrant classmates, Exploring primary pupils' experiences and understandings of 'e-safety', and Pupils' attitudes towards school science as they transfer from an ICT-rich primary school to a secondary school with fewer ICT resources: Does ICT matter? 


\subsection{Volume 16-20 (2011-2015): The emergence of e-learning}

There were 186 articles published in these volumes but no book reviews or information articles. With the increasing number of publications and still having four issues per volume, publishing complete special editions became difficult, so in some cases, these became special sections in regular issues. As a result, this demi-decade had the following Special Issues (Special Sections):

- Online Learning Technologies

- ICT and the Handling of Data, Information and Knowledge

- Educational Challenges: ICT-Based Responses

- Innovative Learning Techniques and Educational Technologies

- From E-Readers and Computer Games to Basketball

- Social Technologies, Videoconferencing, Online and Blended Learning and Modelling

- Intergenerational Learning and Digital Technologies

- Mobile and Panoramic Video in Education

- Educational Challenges in a Digitally Networked World

Again, articles examined education and information technologies in different countries and geographic areas: Arabian Gulf, Australia, Brunei, Egypt, France, Ghana, Greece, Greek-Cypriot area, Hawaii, India, Ireland, Kenya, Macao Portuguese, Malaysia, NATO, Nigeria, Pacific Islands, sub-Saharan Africa, South Africa, Sweden, Tanzania, Uganda, UK, USA, and the Flemish language area.

Multimedia still had a significant presence in articles, along with its special edition. Many of these articles relate to video and the web. Topics included: interactive whiteboards, a web-based multimedia course, videoconferencing, video databases, digital video content, digital video stories, video clips for YouTube, digital storytelling, video capture and access, mobile panoramic video applications, and web-based multimedia.

Social media had just begun to appear at this stage, with some articles relating to Facebook and Twitter. In addition, there was an article looking at: How are campus students using social media to support their studies?

Another new appearance was the design, and use of serious educational games, with articles like: Are serious video games something more than a game? A review on the effectiveness of serious games to facilitate intergenerational learning, Measuring the (dis-)similarity between expert and novice behaviours as serious games analytics, On the cybernetic arrangement of feedback in serious games: A systems-theoretical perspective, and A computer card game for the learning of basic aspects of the binary system in primary education: Design and pilot evaluation.

A few articles dealt with using information technologies to assist deaf students, disadvantaged students, underachievers and to aid digital and social inclusion of students. One article looked at ICT education for older people to facilitate their interactions. 
Technology and software issues were also included, with articles on architectural specifications for systems, the use of laptop computers and mobile phones in education, and one investigating copyrighted internet material and teaching.

Articles on blended learning had just started to appear, including a special issue involving this topic. In addition, distance learning appeared in articles relating to online learning, online communities, e-learning, and an article on E-learning in lifelong education: A computational approach to determining listening comprehension ability.

Articles on Teachers and Teaching included the following topics: Barriers to integrating computers in early childhood settings, Teachers' professional development for ICT integration, Preparing teachers for schooling in the digital age, and ICTmediated teaching/learning systems for elementary school teachers. Some articles were: Constructing knowledge: An effective use of educational technology for teaching Islamic studies in the UK, Teachers' thoughts on e-readers in the elementary school classroom, and It's easier to read on the internet - you just click on what you want to read ...".

As in the previous demi-decades, many articles considered human and social issues relating to education and information technologies. Topics included: Gender differences in attitudes towards learning oral skills using technology, Aligning digital and social inclusion: A study of disadvantaged students and computer access, Information Communication Technology planning in developing countries, and Assessing a novel application of web-based technology to support implementation of school wellness policies and prevent obesity.

\subsection{Volume 21-25 (2015-2020): Mobile and blended learning take centre stage}

These volumes were a very large-scale demi-decade with 859 articles published. There were six special issues (Special Sections):

- A New Culture of Learning: Developing Computing in the Curriculum and Advancing Digital Pedagogy

- Teachers and Social Networking Sites

- Students, Computers and Learning: Where is the Connection?

- Creative Online Collaboration - a Special Challenge for Co-Creation

- The Trends of Blended Learning in South-East Asia

- Learning Management Systems and Big Data Technologies for Higher Education

Many authors wrote articles that examined education and ICT in their own countries. These included education in Australia, Bahrain, Bangladesh, Brazil, Brunei, China, Czech Republic, Denmark, Egypt, England, Fiji, Finland, France, Germany, Ghana, Greece, Hong Kong, India, Indonesia, Iran, Ireland, Jordan, Kazakhstan, Kosovo, Kuwait, Malaysia, Mexico, Morocco, Namibia, Nigeria, Oman, Pakistan, Palestine, Philippines, Poland, Qatar, Romania, Russia, Saudi Arabia, South Africa, Spain, Sweden, Tanzania, Thailand, Trinidad and Tobago, Turkey, UAE, USA, Vanuatu, Vietnam, Wales, Zambia, and Zimbabwe. In addition, some wider-ranging 
articles looked at education and IT in Asia, Europe, South-East Asia, Sub-Saharan Africa, Nordic countries, and globally.

Another article explores the challenges in the Za'atari refugee camp in Jordan using the social media tool WhatsApp. This discussion on mobile phones supported the language teacher development for this broad socio-cultural group.

Massive Open Online Courses (MOOCs) appeared in a big way in this demidecade with 14 articles relating to this. MOOC-related topics included: Affordable Quality Education, Learning Strategies, Motivation and a Sense of Achievement, Quality Factors, Self-Regulated Learning, Drivers and barriers to MOOCs adoption, Learners' Dropout in MOOCs, and an article titled: Are you ready? Self-determined learning readiness of language MOOC learners.

Another popular topic was blended learning, where online learning materials supplement the regular classroom. This topic had a special issue titled The Trends of Blended Learning in South-East Asia. Articles were on topics such as Blended learning and traditional learning, Attributes that support self-regulation, Peer assessment and blended learning, Teaching and learning effectiveness, Self-regulated learning strategies with blended learning, and Blended learning in computing education. Some interesting articles were: Effect of blended learning and learners' characteristics on students' competence: An empirical evidence in learning oriental music, A blended learning course for playfully teaching programming concepts to school teachers, The effect of web based blended learning on students' academic achievement and attitudes towards English course, and Cognitive optimism of distinctive initiatives to foster self-directed and self-regulated learning skills: A comparative analysis of conventional and blended learning in undergraduate studies.

The flipped classroom, which involves blended learning where teachers introduce content to students at home and they work on it at school, had several articles on topics included: Performance and perception in the flipped classroom, Traditional and flipped classroom approaches, Mobile learning for flipped classrooms, Adaptive flipped classrooms based on a learning management system, and Flipped classrooms and students' motivation and academic achievement levels.

The use of information technology to assist the learning of English as a Foreign Language (EFL) also made a significant appearance in articles from Turkey, Greece, Iran, Qatar, Oman, China, and Taiwan. In particular, it was interesting to see six articles dealing with EFL using flipped learning from authors in China, Oman, Turkey, and other countries. A couple of interesting articles were: Is the flipped classroom model for all? Correspondence analysis from trainee instructional media designers, and Student views on the use of flipped learning in higher education: A pilot study.

As in previous demi-decades, social issues were again significant. Articles dealing with a disability included: Interactive whole language e-story for early literacy development in ethnic minority children, Cognitive support embedded in self-regulated e-learning systems for students with special learning needs, Mobile learning as an alternative to assistive technology devices for special needs students, and Assistive technology for students with learning disabilities - A glimpse of the Livescribe pen and its impact on homework completion. The use of badges to support student engagement also relates to special educational needs. Another 
article dealt with collaboration: One for all and all for one - towards a framework for collaboration support systems. Social media issues relating to Facebook and YouTube videos supplemented a special issue on Teachers and Social Networking Sites.

The autism spectrum had several articles: VLEs, social stories and children with autism: A prototype implementation and evaluation, and An immersive virtual reality educational intervention on people with autism spectrum disorders (ASD) for the development of communication skills and problem-solving.

A new area of importance was cyberbullying, particularly concerning adolescent students, with one article titled: Computer-based communication and cyberbullying involvement in the sample of Arab teenagers. Another article offered precautions: Adolescents and Cyber Bullying: The Precaution Adoption Process Model.

The 'One-to-one classrooms' concept, where there is one computer for each student in the classroom was a new feature. Articles included: The effects on the studentteacher relationship in a one-to-one technology classroom, Understanding teachers' reluctance to the pedagogical use of ICT in the 1:1 classroom, Study of a sequence to stimulate the engagement in one-to-one iPad programs at elementary schools, and The stretchiness of learning the digital mystery of learning in one-to-one environments in schools.

Articles on technology were also prominent, particularly on the iPad and tablet computers, including machine learning, augmented reality, virtual schools, cloud computing, and smartboard technology. Articles covered all levels of education, including kindergarten.

\section{Looking back at how things changed over 25 years}

There have been many changes in the field of Education and Information Technologies over the past 25 years. Firstly, there has been a flowering of research interest in the area, reflected in the number of articles published each year. Second, there has been an expansion in the number and nature of devices, software applications, and educational purposes over this period. Of note have been trends towards networked and mobile devices in the hands of learners and fusion of educational management with online learning content servers for teachers. Third, within the pages of EAIT, we have seen a gradual shift from descriptive material to highly focussed in-depth research analytics. For instance, it was not unusual in 1997 to read about computers as an experimental treatment to assist in teaching a regular topic in the school curriculum (e.g., Cox \& Nikolopoulou, 1997). The methodology would be a control v. experimental group with pre/post-test comparisons. Fast-forward to 2020, and we see very detailed statistical examinations of rich data using structural equation modelling (SEM) and bootstrapping to inquire about the development of metacognitive skills (Anthonysamy, 2021). These are only examples of the increasing sophistication found in manuscripts, with perhaps more focus on humans than machines. 


\subsection{Three leading articles}

Quotations from interviewees often illuminate qualitative research. Authors usually craft the selection of such verbatim texts to be illustrative of a theme or to identify the theoretical underpinnings. In this spirit, we have identified three papers that are exceptional in one way or another to illustrate some essential emerging characteristics of EAIT articles.

The first is an article about techno-optimism and pessimism (Tomczyk et al., 2021). Two aspects make it a leader for EAIT. Firstly, over the 25 years, this article had the most research organisation countries involved (8). Second, the lead author became an Associate Editor of EAIT in 2021! The article described the formulation of a survey instrument. Data were gathered from all the countries using this instrument. The article then provides teacher techno-optimism results through statistical and descriptive analysis.

The following leading article has the most citations over the 25-year period (Jensen \& Konradsen, 2018). It had been cited 265 times at the time of writing. The co-authors work in a Faculty of Health and Medical Sciences in Denmark. This aspect shows that researchers from disciplines other than education can make wellreceived contributions to the journal. While the previous leading article was published with Open Access, this one is available as subscriber content. Going beyond this single case to the ten most highly cited articles in 25 years of EAIT, we find papers published from 2001 to 2017. Thus, even relatively old articles can be in this esteemed category. Topics range from the pedagogy/technology debate (the UK, 2001), digital badges (the USA, 2013) to smartphones in the classroom (Brunei, 2017). These topics were evidently of interest worldwide, and early publication in EAIT allowed authors to be picked up and cited in the continuing academic discussion.

The leading published article with most co-authors had 14 names (Westera, et al., 2020). It emerged from collaboration across five countries in a European flagship project on profound game technologies. The size of the project indicates the scale of the work, involving a wide range of promising technologies and educational approaches: re-usable over many platforms; real-time facial emotion recognition; automated difficulty adaptation; stealth assessment; natural language processing; and believable non-playing characters (emotional and socio-cultural, non-verbal bodily motion, and lip-synchronised speech).

\subsection{Growth of literature reviews}

Over the years, systematic literature reviews have become more popular. To quantify this statement, the authors examined the database of articles published in EAIT to see if the word 'review' occurred in the title or abstract or if they found 'systematic' in the abstract. Following an inspection of $20 \%$ of entries, the authors found that 'review' in the title was the best way to detect such articles. Table 5 shows the recent rapid rise of reviews. 
Table 5 Proportion of 'Literature Review' articles published

\begin{tabular}{llll}
\hline Demi-decade & Articles & Reviews & $\begin{array}{l}\text { Proportion of } \\
\text { 'review' articles }\end{array}$ \\
\hline $1996-2000$ & 100 & 0 & $0.0 \%$ \\
$2001-2005$ & 109 & 1 & $0.9 \%$ \\
$2006-2010$ & 136 & 2 & $1.4 \%$ \\
$2011-2015$ & 287 & 5 & $1.7 \%$ \\
$2016-2020$ & 878 & 39 & $4.2 \%$ \\
\hline
\end{tabular}

Such reviews can be informative, but they rely upon enough published articles based upon data for their value. More papers from a variety of databases increase the value of such reviews. In 2021 so far, the average number of papers considered in review articles has been 46. Looking forward, this might become the lower bound we will see mentioned in any future abstract. In addition, reviews have the power to compare methods and efficacy over many contexts when they employ a standardised system equivalence. For instance, Cohen's $d$ or effect size is a dimensionless measure of relative effectiveness. The use of these techniques will ensure article quality and value for readers as we go forward.

\subsection{Journal editors over the years}

Over its history EAIT has had a number of different Editors. The early volumes had only one or more Editors, while the later volumes had an Editor-in-Chief and several Associate Editors

- Volume 1 (1996)

- Editors: Betty Collis (The Netherlands) and Brian Samways (UK)

- Volume 2 (1997)

- Editors: Betty Collis, Brian Samways and Holly Jobe (USA)

- Volume 3 (1998)

- Editors: Betty Collis, Brian Samways and John Olson (Canada)

- Volume 4 (1999) - Volume 11 (2006)

- Editor-in-Chief: Deryn Watson (UK)

Volume 11, Issue 3-4, Editors Bob Munro and Deryn Watson

- Volume 12 (2007) - Volume 14 (2009)

- Editor-in-Chief: Ian Selwood (UK)

Volume 14, Issue 3, 4 Editor-in-Chief: Arthur Tatnall (Australia) 
- Volume 15 (2010) Editor-in-Chief: Arthur Tatnall

- Volume 15 Issue 4: Associate Editors: Bill Davey (Australia) and Tony Jones (Australia)

- Volume 16 (2011) - Volume 23 (2018)

- Editor-in-Chief: Arthur Tatnall

- Associate Editors: Bill Davey and Tony Jones

- Volume 17-23 (2012-2018)

- Editor-in-Chief: Arthur Tatnall

- Associate Editors: Bill Davey and Tony Jones

Volume 23, Issue 4: Associate Editors: Bill Davey, Tony Jones, Therese Keane (Australia)

- Volume 24 (2019)

- Editor-in-Chief: Arthur Tatnall

Volume 24, Issue 1: Associate Editors: Bill Davey, Tony Jones, Therese Keane

Volume 24, Issues 2-6: Tony Jones retired as an Associate Editor, and Associate Editors then were: Bill Davey and Therese Keane

- Volume 25 (2020)

- Editor-in-Chief: Arthur Tatnall

- Associate Editors: Bill Davey, Therese Keane, Andrew Fluck (Australia) and John Impagliazzo (USA)

In Volume 26 (2021), Bill Davey retired as an Associate Editor and over the year, in addition to Therese Keane, Andrew Fluck and John Impagliazzo, five new Associate Editors were appointed: Ford Lumban Gaol (Indonesia), Shah Miah (Australia), Łukasz Tomczyk (Poland - Italy), Javier Osorio (Spain) and Tiko Iyamu (South Africa).

\section{The future}

Based on this tabulation and analysis, what could the next decade hold? First, the recent addition of EAIT to the Social Science Citation Index (SSCI) in the 'Education \& Educational Research' category was a positive development. SSCI is part of the Web of Science, a multidisciplinary index to the journal literature of the social sciences (Web of Science Group, 2020). Furthermore, the reported high Impact Factor of EAIT in that index has dramatically increased submissions, as occurred in Volume 25.

A sneak peek into articles already published in 2021 shows - unsurprisingly - 'COVID' has become a ubiquitous keyword. However, going on historical trends, 
co-formulated by submitting authors and the editorial team who select appropriate content, we can expect a 33:33:33 mixture. Approximately one-third of the keywords have (and will probably be) education-related; another third will be technology descriptions; and the final third will be an eclectic mix of research, evaluation, neuroscience - and hopefully, efficacy/impact on learning! The technological trends are captured quite well in the Horizon Report: Trends series, which forecasts the emergence of machine learning/artificial intelligence (AI). Industrial trend reports focus on global connectivity, system resilience, trust and equity, (quantum) Artificial Intelligence (engineering), and simulations (Buchholz et al., 2020; Burke, 2020; McKinsey and Co, 2020). The rise of AI systems is epitomised by voice assistants (digital devices listen and return audio answers) and the growing size of neuro processing units in car systems-on-a-chip, which are up to three times the size of the central processing unit in some cases (Bos, 2019). In addition, greater communication bandwidth with reduced latency will provide students with excellent opportunities for virtual field trips and interaction with virtual peers combined with AI.

\subsection{Predictions for the next ten years}

1511 articles were published in EAIT from 1996-2020 (25 years). This number includes book reviews (39), information (9), and editorials. Figure 1 shows the historical number of articles published each year and the extrapolation of future articles using the AAA version of the exponential smoothing (ETS) algorithm (Winters, 1960). The prediction was based on volumes published since 2011 , because the quantities changed significantly from that year.

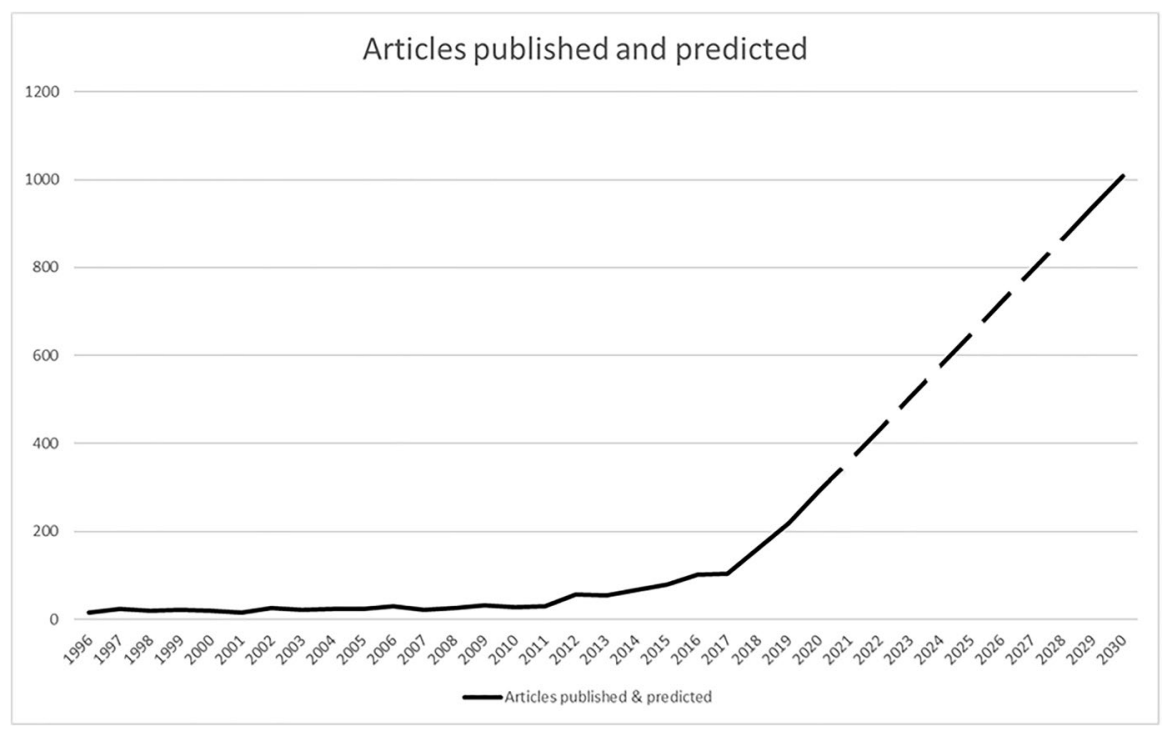

Fig. 1 Annual number of EAIT articles published and predicted 
In 2021 the journal received 2,583 submissions and published 252 (an acceptance rate of about $15 \%$ ), but the journal editors estimate this rate may drop lower to keep pace with the volume of articles.

\section{Conclusion}

EAIT is very proud of all contributing authors, reviewers, publishing staff, editorial team and board, and of course, all our readers. The past 25 years have been an era of growth, more strongly in the most recent decade.

The editorial team expects continued growth in citations, journal impact factors, and international collaborations in the future. As the number of submissions also climbs, we will be more selective with manuscripts. More extensive studies with real value for a global readership are more likely to be published than small studies conducted in a single class, institution, or country. The journal is now ranked fifth in the Google Scholar rankings for Educational Technology (2022), leaving room for improvement.

There is little doubt that computers have changed education a great deal since the start of this journal in 1996. Equally, many researchers are clearly of the opinion there will be more changes in the future. Significant changes to the curriculum may be in store since all new technologies make some topics less relevant to the lives of younger citizens. EAIT will be supporting you as this happens!

Funding Open Access funding enabled and organized by CAUL and its Member Institutions

\section{Declarations}

Conflict of interest No conflicts.

Open Access This article is licensed under a Creative Commons Attribution 4.0 International License, which permits use, sharing, adaptation, distribution and reproduction in any medium or format, as long as you give appropriate credit to the original author(s) and the source, provide a link to the Creative Commons licence, and indicate if changes were made. The images or other third party material in this article are included in the article's Creative Commons licence, unless indicated otherwise in a credit line to the material. If material is not included in the article's Creative Commons licence and your intended use is not permitted by statutory regulation or exceeds the permitted use, you will need to obtain permission directly from the copyright holder. To view a copy of this licence, visit http://creativecommons.org/licenses/by/4.0/.

\section{References}

Anthonysamy, L. (2021). The use of metacognitive strategies for undisrupted online learning: Preparing university students in the age of pandemic. Educ Inf Technol, 26, 6881-6899. https://doi.org/10. 1007/s10639-021-10518-y

Bos, C. (2019). Tesla's New HW3 Self-Driving Computer - It's A Beast (CleanTechnica Deep Dive). CleanTechnica. https://cleantechnica.com/2019/06/15/teslas-new-hw3-self-driving-computer-its-abeast-cleantechnica-deep-dive/ 
Buchholz, S., Bechtel, M. \& Briggs, B. (eds) (2020). Tech Trends 2021. Deloitte Insights https://www2. deloitte.com/content/dam/insights/articles/6730_TT-Landing-page/DI_2021-Tech-Trends.pdf

Burke, B. (2020). Top Strategic Technology Trends for 2021. Gartner. https://www.gartner.com/en/publi cations/top-tech-trends-2021

Caspersen, M.E., Gal-Ezer. J., McGettrick, A. \& Nardelli, E. (2018). Informatics for All: The strategy. ACM Europe \& Informatics Europe. https://www.informatics-europe.org/component /phocadownload/category/10-reports.html?download=75:informatics_for_all_2018

Collins English Dictionary. (2021). Definition of 'ICT'. Retrieved from https://www.collinsdictionary. com/dictionary/english/ict

Collis, B., \& Samways, B. (1996). Editorial:. Education and Information Technologies, 1(1).

Cox, M., \& Nikolopoulou, K. (1997). What information handling skills are promoted by the use of data analysis software? Education and Information Technologies, 2, 105-120. https://doi.org/10.1023/A: 1018644709701

Educause (2020). The Horizon Report Trends. https://er.educause.edu/-/media/files/articles/ 2020/3/er20_ 1114.pdf

Goldweber, M., Impagliazzo, J., Bogoiavlenski, I. A., Clear, A. G., Davis, G., Flack, H., . . . Rasala, R. (1997). Historical Perspectives on the Computing Curriculum (report of the ITiCSE'97 working group on historical perspectives in computing education). ITiCSE-'97 Working Group Reports and Supplemental Proceedings, 94-111.

Goodson, I., \& Anstead, C. (1992). Through the Schoolhouse Door: Curriculum Studies and Historical Methods. In I. F. Goodson \& J. M. Mangan (Eds.), History Context and Qualitative Methods in the Study of Education, RUCCUS Occasional Papers (Vol. Vol 3). University of Western Ontario.

Google Scholar (2022). Top publications: Educational Technology. https://scholar.google.com/citations? view_op=top_venues\&hl=en\&vq=soc_educationaltechnology

Howell, M. C., \& Prevenier, W. (2001). From Reliable Sources, An Introduction to Historical Methods. Cornell University Press.

Jensen, L., \& Konradsen, F. (2018). A review of the use of virtual reality head-mounted displays in education and training. Educ Inf Technol, 23, 1515-1529. https://doi.org/10.1007/s10639-017-9676-0

McKinsey \& Co. (2020). The top trends in tech. Author. https://www.mckinsey.com/ /media/McKin sey/Business\%20Functions/McKinsey\%20Digital/Our\%20Insights/The\%20top\%20trends\%20in\% 20tech\%20final/Tech-Trends-Exec-Summary

Oxford Reference. (2021). Information Technology - definition. Retrieved from https://www.oxfordrefe rence.com/view/10.1093/oi/authority.20110803100003879

Tiffen, J. (1996). The virtual class is coming. Educ Inf Technol, 1, 143-150. https://doi.org/10.1007/ BF00168278

Tomczyk, Ł., Jáuregui, V. C., de La Higuera Amato, C. A., et al. (2021). Are teachers techno-optimists or techno-pessimists? A pilot comparative among teachers in Bolivia, Brazil, the Dominican Republic, Ecuador, Finland, Poland, Turkey, and Uruguay. Educ Inf Technol, 26, 2715-2741. https://doi.org/ 10.1007/s10639-020-10380-4

Web of Science Group. (2020). Social Sciences Citation Index - Education and Information Technologies. Retrieved from https://mjl.clarivate.com:/search-results?issn=1360-2357\&hide_exact_match_ $\mathrm{fl}=$ true\&utm_source=mjl\&utm_medium =share-by-link\&utm_campaign=search-results-share-thisjournal

Westera, W., Prada, R., Mascarenhas, S., Mascarenhas, S., Santos, P. A., Dias, J., Guimarães, M., Georgiadis, K., Nyamsuren, E., Bahreini, K., Yumak, Z., Christyowidiasmoro, C., Dascalu, M., GutuRobu, G., \& Ruseti, S. (2020). Artificial intelligence moving serious gaming: Presenting reusable game AI components. Educ Inf Technol, 25, 351-380. https://doi.org/10.1007/s10639-019-09968-2

Winters, P. R. (April 1960). "Forecasting Sales by Exponentially Weighted Moving Averages". Management Science. 6 (3): 324-342. doi:https://doi.org/10.1287/mnsc.6.3.324

Publisher's note Springer Nature remains neutral with regard to jurisdictional claims in published maps and institutional affiliations. 